\title{
Introduction to the second edition: novelties and advances
}

\author{
Roberta Capello and Peter Nijkamp
}

\section{THE GOAL OF THE NEW EDITION}

The space-economy has never been static, but has always shown a state of flux. Regions are normally in transition; they are work in progress. As a consequence, we observe a complex evolution of regional systems that varies between growth and decline. Static location and allocation theories may be helpful in understanding underlying structures in regional economies, but do not offer a full-scale picture of the development of multi-actor processes and of the perpetual or temporal impediments for regional growth and prosperity. The conceptualization and solid explanation of regional growth, and differences therein, is still largely a mystery for the research community in many countries. There is no uniform panacea for enhancing or accelerating the development trajectory of regions in a national or supranational economy. Therefore, regional policy is still in many cases a black box; the outcomes of intensified regional growth strategies are often largely unpredictable. Best guesses are more common than testable and operational estimates of policy impacts.

Against the above-mentioned backgrounds, the editors of the Handbook of Regional Growth and Development Theories published a decade ago a comprehensive volume with a rich collection of advanced contributions on the above challenges in regional economics and regional science. In the ten years since then the world, both the empirical regional world and the theoretical and empirical reflection on growth and development issues, has not come to a standstill. We have become sadder and wiser after economic crises, regional fragmentation trends, the introduction of radical technological innovation, and the awareness of failures of regional policy. However, we have also enriched our knowledge horizon, with new insights and new methods and theories of regional analysis. The time has now come to take a refreshing and new look at the achievements of regional growth and development theories.

Ten years after the publication of the first edition of the Handbook of Regional Growth and Development Theories, we were asked by the publisher to update the volume. At first glance this request seemed exaggerated, since not much new appeared to have happened in a so short period of time. After serious thoughts, however, we realized that in the past ten years, new insights into the explanation of regional growth had been put forward, and some theories, which ten years ago were not so attractive, had come to the fore. We, therefore, decided to accept the proposal, being sure that realization of this request could lead to an interesting scientific work with a decisive value added.

Our effort has been to create a new edition enriched with the novelties of these past years. With this goal in mind, we first identified some theories and issues that were missing in the first publication and that gained in the meantime great importance in the interpretation of regional growth. For this reason, various new chapters were added. 
Secondly, we asked the authors of the original chapters to think about new ideas that have been developed over the past ten years, and to revise their chapters accordingly. The result is a new edition comprising new or totally revised chapters. The structure of the book has remained the same. In each of the five parts of this volume, the reader can enjoy new chapters that reinforce and, moreover, complement the previous chapters. This is especially true for the Part $\mathrm{V}$ on regional growth and development policies.

\section{NEW CHAPTERS IN THIS EDITION}

To give an idea of the scientific novelties of this Handbook, the new chapters offer insights into theories that have recently gained importance. The first new theory treated in this new edition is the relationship between leadership and regional growth (Chapter 5). Despite the importance of institutions for social scientists since the beginning of the 1900s (Weber 1920, 1968), the link between institutions and economic development started to be taken into consideration during the 1990s, and only since the 2010s has particular attention been paid to the quality of institutions in regard to regional development growth (Rodriguez-Pose 2013). It is worth adding a review on how this subject has been treated in the literature.

The second new theme is the advent of new industrial organizations that are taking place as the result of the globalization process that is characterizing modern economies. The global value chains are now a reality, and the effects that their existence generates on regional development is still an open question. A new chapter is therefore devoted to this issue, presenting a critical and structured review of potential differentiated growthenhancing effects that foreign direct investments and global value chains might have on regions (Chapter 11).

The third new chapter makes an effort to revise theories that underline the linkage between innovation and regional development, with the specific aim to highlight how space is conceived in each theory (Chapters 12 and 13). Reading the chapters, it becomes evident that the increasing interpretative power of theories on innovation and regional development is strongly linked to the capacity of these theories to make space play an active role in the innovation process. Only when knowledge creation and innovation processes are not merely made dependent on the mere presence of actors and functions (research and development laboratories, and universities), but also on the socio-economic relationships that exist in society, are they able to explain the long-term competitiveness of local areas (Capello, Chapter 12 and Lenzi, Chapter 13 in this volume). All this is of great importance once innovation policies designed for the characteristics of the local areas have been identified.

The concept of space, and of proximity, has evolved over time, and achieved particular attention over the past years. In this sense, a chapter on the different conceptualizations of proximity was necessary, and has been added to this edition (Chapter 16). From geographical proximity, theories have moved to relational, organizational and cognitive proximity. All types of proximities enlarge and enrich the spectrum of interpretations of space and its role in local development (Rallet and Torre 1995; Boschma 2005; Torre and Wallet 2014; Asheim et al. 2016). Space shapes propensities to cooperation and innovation; it supplies the cognitive preconditions for innovation through the presence 
of context-specific know-how, density of information spillovers and trust in interpersonal relationships; and it reduces strategic uncertainty, intrinsic in any innovation process (Camagni, 2015; Capello and Lenzi, 2018). The concept of cognitive clusters has been launched; a review is presented in Chapter 18 of this volume.

Part V, on regional growth and development policies, has been enlarged with methodological chapters containing the most recent methods of policy evaluation. Both the US and Europe have registered new laws asking for the ex-ante and ex-post assessment of local development policies. These official requests have obliged scientists to develop advanced and sophisticated evaluation methods that over the past ten years have become popular. For this reason, this final part of the Handbook, dedicated to policies, has been strengthened with chapters on evaluation methodologies (Chapters 27, 28 and 29).

\section{REVISED CHAPTERS IN THIS EDITION}

The chapters from the previous edition have all been updated, not merely with new references but with new ideas. We leave it to the reader to enjoy the novelties by reading the book. Here, we provide some arbitrarily chosen examples of new insights in the previous edition's chapters.

In the theoretical sphere, one of the novelties that emerged is the effort made over the past ten years to merge the rigour of formal economic models with the rich interpretative power of qualitative approaches. The new economic geography (Krugman 1991) and the new growth theories (Romer 1986; Lucas 1988) had partly resolved the problem from which regional, qualitative in nature, development theories had always suffered: their inability to construct formal models which combine specifically territorial features, such as externalities and agglomeration economies, with macroeconomic laws and processes of growth. However, they had done so by introducing agglomeration advantages in stylized form, through increasing returns, cancelling out the territorial dimension, and therefore ignoring synergy, cooperation, relationality and collective learning. In so doing, it divested these theories of the aspect of greatest importance to regional economists, namely, space as territory, referring to a system of localized technological externalities, or a set of material and non-material factors which by virtue of proximity and reduced transaction costs act upon firms' productivity and innovativeness (Capello 2009).

This consideration had been presented in the first edition of this Handbook. Over the past ten years, however, an interesting effort has been made to insert qualitative aspects coming from regional development theories (for example, trust, sense of belonging, district economies, urbanization economies, quality of governance, synergy, cooperation and relationality) in a formalized (macroeconomic) growth model. In this way, the theoretical modelling exercise can achieve more of the rigour of the formal approaches and can be enriched with the deep interpretative power of qualitative theories (Chapter 2 in this volume). This step forward was made possible also thanks to the richness of data on intangible elements of 'territorial capital', referring to all geographically bounded assets of a territorial nature - natural or artificial, material or immaterial, cognitive, social, cultural or characterized by a strong identity - on which the competitiveness potential of regions and places rests (Chapter 7 in this volume).

In this context, over the past ten years, a decisive advancement has been provided by 
explicitly identifying the laws of accumulation and depletion of the different categories of territorial capital assets; the intrinsic difference highlighted among the modalities by which the single components of territorial capital are accumulated, put in value, but also are subject to de-cumulation, trivialization, destruction and possibly reuse for different purposes. All this is of great importance for the conception and design of nonconventional policies, going beyond the usual sectoral approach or the pure distinction between the private versus the public actors involved (Chapter 7 in this volume).

In the empirical sphere, the new edition presents some advances, of which we report here only some examples. A first important novelty lies in an advanced review on the empirical methods for measuring regional convergence, trying to reply to the question - which never found a sound reply - on how funds can be allocated in order to promote regional convergence (Chapter 21 in this volume). Moreover, the new edition presents advances in well-known techniques such as input-output analysis, highlighting the ways in which input-output systems are being nested/embedded within more extensive economy-wide models or integrated with other models to generate a more comprehensive analysis of single and multi-regional economies. These models have been constructed using social accounting matrix databases; they range in scope from regional and interregional social accounting models (SAMs) to computable general equilibrium (CGE) models that are then used for a variety of impact analysis (Chapter 24 in this volume).

In this new edition, the reader can enjoy other new insights that made our work as editors extremely interesting and stimulating. We hope the reader agrees with us that our task was worth the effort.

\section{REFERENCES}

Asheim, B.T., M. Grillitsch and M. Trippl (2016), 'Regional innovation systems: past-presence-future', in R. Shearmur, C. Carrincazeaux and D. Doloreux (eds), Handbook on the Geographies of Innovation, Cheltenham, UK and Northampton, MA, USA: Edward Elgar, pp. 45-62.

Boschma, R. (2005), 'Proximity and innovation. a critical assessment', Regional Studies, 39, 61-74.

Camagni, R. (2015), 'Towards creativity-oriented innovation policies based on a hermeneutic approach to the knowledge-space nexus', in A. Cusinato and A. Philippopoulos-Mihalopoulos (eds), Knowledge-creating Milieus in Europe: Firms, Cities, Territories, Berlin: Springer Verlag, pp. 341-58.

Capello, R. (2009), Regional Economics, London: Routledge.

Capello, R. and C. Lenzi (2018), 'Regional innovation evolution and economic performance', Regional Studies, 29 November, doi.org/10.1080/00343404.2018.1502421.

Krugman, P. (1991), Geography and Trade, Cambridge, MA: MIT Press.

Lucas, R. (1988), 'On the mechanics of economic development', Journal of Monetary Economics, 22, 3-42.

Rallet, A. and A. Torre (1998), 'On geography and technology: proximity relations in localised innovation networks', in M. Steiner (ed.), From Agglomeration Economies to Innovative Clusters, London: Pion Editor, pp. 41-56.

Rodríguez-Pose, A. (2013), 'Do institutions matter for regional development?', Regional Studies, 47, $1034-47$.

Romer, P. (1986), 'Increasing returns and long-run growth', Journal of Political Economy, 94, $1002-37$.

Torre, A. and F. Wallet (eds) (2014), Regional Development and Proximity Relations, Cheltenham, UK and Northampton, MA, USA: Edward Elgar.

Weber, M. (1920), Die protestanitische Ethik and der 'Geist' des Kapitalismum, vol. 1, Tübingen: Mohr.

Weber, M. (1968), Economy and Society, trans. G. Roth and C. Wittich, New York: Bedminster Press. 